\section{EVALUATE PARENTAL BELIEFS ON THE ORIGINS OF THE DENTAL FEAR IN 6-12 YEAR OLD CHILDREN REFFERING TO PEDIATRIC}

\author{
Z. Ghazavi ${ }^{1}$, F. Keshani², M. Jafarzadeh² \\ ${ }^{1}$ Nursing and Midwifery Faculty - Psychiatric \\ Nursing, ${ }^{2}$ Dentist Faculy, Isfahan University of \\ Medical Science, Esfahan, Iran
}

Introduction: Dental fear leads to lack of child cooperation and in general without the patient cooperation, success in remedy is impossible.

Methods and materials: This descriptive, analytical , cross sectional study was Carried out on 200 parents of 6-12 year - old children reffering to Isfahan dental university . the level of dental fear in these children was screened using the dental subscale of the children's fear survey schedule(CFSS-DS). This questionnaire consists of 15 times and each item include 5 choices. Total scores Ranged from 15 to 75 . Based on scores children were divided into 2 groups: Low fearful group ( scoring 25 or less) and high fearful group(scoring 37 or more).

Results: There was a reversed significant corrolation between the average of the fear score and the age of the children , I $n$ the high fearful group most of the parents(31\%) chose previous dental experiences as the cause of their child's fear. There was no significant relation between parental belief and their gender, the level of education, the level of their fear and the child's a age and fear score.

Conclusion: According to the parent's beliefs , previous dental experience was a major factor in the development of childhood dental fear. Temperamental factors also played a role in some of the fearful children. Most of the parents in high fearful group attributed their child's fear to the external factor's and seemed unable to control and prevent it.

\section{BEYOND STEREOTYPES: AN ANALYSIS OF HOW AUTISTIC SPECTRUM DISORDER IS DEPICTED IN MOVIES, 1962-2009}

\author{
V. Palanivel ${ }^{1}$, M.A. Anjay ${ }^{2}$, J. Palanivel ${ }^{3}$
}

${ }^{1}$ Department of Neurosciences, Great Ormond Street Hospital for Children, London, ${ }^{2}$ Department of Paediatrics, Addenbrookes Hospital, Cambridge, ${ }^{3}$ Department of Paediatrics, James Paget University Hospital, Great Yarmouth, UK

Background \& Aims: Depiction of autistic spectrum disorders (ASD) in mass media is an indicator of how this population is perceived by society.

We aimed to:

- Identify all English movies which depict characters with possible ASD.

- Describe the socio-epidemiologic and clinical traits of these characters.

- Critically analyse broad themes emerging from this.

Methods: The Internet Movie Database, (IMDB) was searched using keywords "autism", "autistic" and "Asperger's syndrome". The same keywords along with "movies", "film" or "cinema" were entered into two leading internet search engines to identify movies missed by IMDB search. The plot synopsis and reviews were analysed.

Results: A total of 89 movies were identified, with the earliest being in 1962 . Nearly $50 \%$ were released in the last 10 years. The genres were predominantly drama $(69 \%)$ and thriller $(21 \%)$. The characters were mostly children (47\%) and adolescents (11\%). The male: female ratio was 2:1.Many movies have concentrated on the extreme features of autism, with co-morbidities, thus reinforcing negative stereotypes. High functioning autism is given undue prominence. Some movies depict autistic characters being ridiculed and discriminated. A large number portray children in the background of horror/gore. Unconventional treatments are portrayed frequently. The parents are often shown as being unable to cope and frustrated with the medical establishment. The multi-disciplinary approach to the care of autistic children is notable by its absence.

Conclusions: The depiction of ASD in movies is generally inaccurate, thus misinforming the public and reinforcing myths and stereotypes surrounding this condition. 